\title{
AUTOFLUORESCENCE IN PAP STAIN IN THE SPUTUM OF SUSPECTED PULMONARY TUBERCULOSIS AND COMPARE WITH OTHER AFB STAINS
}

\author{
Mani Krishna ${ }^{1}$, Adesh Kumar ${ }^{2}$
}

${ }^{1}$ Associate Professor, Department of Pathology, UP Rural Institute of Medical Sciences \& Research, Saifai, Etawah, Uttar Pradesh. 2Professor, Department of Pulmonary Medicine, UP Rural Institute of Medical Sciences \& Research, Saifai, Etawah, Uttar Pradesh.

\section{ABSTRACT}

\section{BACKGROUND}

Tuberculosis is an infectious disease caused by mycobacterium tuberculosis. It primarily affect lungs and can also affect intestine, meninges, bones and Joints, lymph node, skin and other tissues of the body. There are various methods for the diagnosis of tuberculosis, such as sputum examination of tubercular bacilli by Ziehl-Neelsen staining, demonstration of tubercular bacilli by Auramine-Rhodamine staining and culture in LJ medium. Papanicolaou stain is widely used in routine cytological evaluation of samples derived from the respiratory tract and eosin to be responsible for the autofluorescence.

\section{MATERIAL AND METHOD}

Present study was done clinically suspected tubercular patients from January to July 2015. On all received samples ZN stain, fluorescent stain and PAP stain was applied.

\section{RESULT}

Among the clinically suspected patients 650 (35.35\%) was diagnosed with tuberculosis. Male-to-female ratio was 2.76:1, Tuberculosis was diagnosed in 315 (16.75\%) cases with Ziehl-Neelsen staining with fluorescent staining in 611 (32.79\%) cases and Autofluorescence in 650 (35.35\%) cases.

\section{CONCLUSION}

In present study, fever was chief clinical complaint. Males are more diagnosed with tuberculosis than females. Autofluorescent staining is slightly more sensitive than the Auramine-Rhodamine and more ZN staining in demonstration of AFB in the samples.

\section{KEYWORDS}

Mycobacterium Tuberculosis, Acid Fast Bacilli (AFB), Ziehl-Neelsen (ZN) Staining, Fluorescent Auramine Rhodamine (AR) Staining, Autofluorescence, PAP Stain.

HOW TO CITE THIS ARTICLE: Krishna M, Kumar A. Autofluorescence in Pap stain in the sputum of suspected pulmonary tuberculosis and compare with other AFB stains. J. Evolution Med. Dent. Sci. 2016;5(16):755-757, DOI: 10.14260/jemds/2016/175

\section{INTRODUCTION}

Tuberculosis is one of the important communicable disease which remains a world-wide public health problem despite the fact that the causative organism was discovered more than 100 years ago and highly effective drugs and vaccine are available. Koch first described the tubercle bacilli in 1882, which is now known as mycobacterium tuberculosis. Mycobacteria are now known to comprise a large group of acid-fast, alcohol-fast, aerobic or micro-aerophilic, non-spore forming, non-motile bacilli. ${ }^{1}$

In stained smears of pathological material, $\mathrm{M}$. tuberculosis is seen as slightly bent rods, 2-4 um long and 0205 um wide, which may be evenly stained or beaded and granular. On solid or liquid media the bacteria tend to be parallel and form long threads or cords. ${ }^{2}$

Commonly fever is low grade and appearing late each afternoon and then subsiding and night sweats with progressive pulmonary involvement, increasing amount of sputum, at first mucoid and later purulent.

Financial or Other, Competing Interest: None.

Submission 14-01-2016, Peer Review 09-02-2016,

Acceptance 13-02-2016, Published 23-02-2016.

Corresponding Author:

Dr. Mani Krishna

Department of Pathology,

UP Rural Institute of Medical Sciences \& Research,

Saifai, Etawah,

Uttar Pradesh.

E-mail: drmanikrishna@gmail.com

DOI: $10.14260 /$ jemds/2016/175
Many laboratories prefer Rhodamine Auramine method of staining AFB over carbol fuchsin stain because the fluorescing bacilli are more readily detected. Auramine stained smears are scanned under low magnification than fuchsin stained smears, thus permitting a large area of the smear to be examined in shorter period of time. ${ }^{3}$

Ghali et al. (1984). ${ }^{4}$ first demonstrated auto fluorescence of pneumocystic carinii in pap stained smears. Their results indicated eosin to be responsible for the autofluorescence. The main components of pap stain being OG-6, EA-65 or EA-50 (Cytoplasmic stains). Papanicolaou stain is widely used in routine cytological evaluation of samples derived from the respiratory tract. Its value in the fluorescence microscopic diagnosis of various pulmonary infectious diseases is well established. 5 In PAP stained smears the slightly curved, beaded tubercle bacillus may be readily identified. ${ }^{6}$

Currently, there is scant data regarding the $\mathrm{ZN}$, Rhodamine Auramine fluorescent staining and Autofluorescent staining on sputum samples.

\section{MATERIAL AND METHODS}

This study was conducted in Department of Pathology and Pulmonary Medicine of Rural Institute of Medical Sciences and Research Saifai Etawah (UP) from January to July 2015; 1949 cases were included in present study, Sputum were collected from a total 1949 patients with clinically suspected tuberculosis. Three smears were prepared from each sample (Two dry and one wet smear). Three smear was stained by routine Ziehl-Neelsen method and other by fluorescence stain Auramine-Rhodamine and PAP (Papanicolaou) stain. 
By Ziehl-Neelsen stain AFB stain pink curve/straight beaded rods against blue background by AuramineRhodamine stain AFB appears as bright reddish-yellow fluorescing rods against a dark background and by Papanicolaou stain fluorescent bacilli appeared as slender, often beaded, yellow-green, straight or slightly curved rods of relatively uniform length against a dark background.

\section{METHOD OF STAINS}

\section{Ziehl-Neelsen (ZN) Stain}

1. Cover the whole surface of the slides with carbol fuchsin. Heat gently until vapor rises. Leave the warm stain for at least 5 minutes.

2. Rinse the slide gently under tap water until all macroscopically visible stain has been washed away. Replace the decolorized slides on the rack and cover each slide with the decolorizing solution for three minutes. Rinse each slide again gently under tap water until all macroscopically visible stain has been washed away.

3. Replace decolorized, rinsed slides on slide-rack and flood smear with methylene blue solution for one minute. Rinse each slide gently under tap water and allow to dry in open air.

\section{Auramine-Rhodamine Stain}

For staining, the slides must be placed on a staining slide rack over the sink with the smeared side uppermost.

1. Cover the whole surface of the slides with Auramine 0 solution and stain for 15 minutes.

2. Rinse each slide gently with water until all macroscopically visible stain has been washed away. Replace the decolorized slides on the rack and cover each slide with the acid alcohol solution for two minutes. Rinse each slide again gently with water until all stain has been washed away.
3. Replace decolorized, rinsed slides on slide rack and flood smear with potassium permanganate solution for two minutes. Rinse the slide gently with water until all stain has been washed away and allow to dry in open air.

Papanicolaou (PAP) Stain.

1. The slide is dipped in a mixture of ethanol-ether for thirty minutes to fix the smear for PAP stain.

2. Take the fixed smears and hydrate them through $80 \%$, $70 \%, 50 \%$ alcohol to distilled water.

3. Place the smears in Harris' Hematoxylin solution for four minutes.

4. Wash in running tap water.

5. Dehydrate upto $95 \%$ ethyl alcohol.

6. Stain the slides with OG-6 (Orange-6) solution for 1-4 minutes.

7. Rinse the slide 10 times in $95 \%$ alcohol.

8. Stain in EA-36 (Eosin-A) solution for 2-4 minutes.

9. Rinse the slide in three jars containing $95 \%$ alcohol.

10. Dehydrate, clear and mount the slide.

\section{RESULTS}

In the present study, a total of 1949 consecutive clinical sample sputum from 1949 clinically suspected cases of pulmonary tuberculosis, received in the Department of Pulmonary Medicine. Total number of AFB positive smears was 650 and negative 1299. Male and Female ratio was 2.76:1. The clinical presentation of tuberculosis is usually fever, cough, sputum, night sweat, haemoptysis, dyspnoea, weight loss and anorexia. Fever was a chief clinical complaint. AFB smears was positive with ZN stain in $315(16.16 \%)$ cases and with fluorescent staining (AR) in 611 (31.34\%) cases and Autofluorescence in pap stain in $650(33.35 \%)$ cases. [Table 1] AFB smears was negative with ZN stain in 335 cases and with AR stain in 39 cases.

\begin{tabular}{|c|c|c|c|c|c|}
\hline $\begin{array}{c}\text { Kind of } \\
\text { Specimen }\end{array}$ & $\begin{array}{c}\text { Total No. of } \\
\text { Cases }\end{array}$ & $\begin{array}{c}\text { Total No. of AFB Positive } \\
\text { Smear }\end{array}$ & $\begin{array}{c}\text { ZN } \\
\text { Positive }\end{array}$ & AR Positive & AF Positive \\
\hline Sputum & 1949 & $\begin{array}{c}650 \\
(33.35 \%)\end{array}$ & $\begin{array}{c}315 \\
(16.16 \%)\end{array}$ & $\begin{array}{c}611 \\
(31.34 \%)\end{array}$ & $650(33.35 \%)$ \\
\hline \multicolumn{2}{|c|}{ Table 1: Distribution of AFB Positive Results with ZN, AR and AF Methods in the Sputum Sample } \\
\hline
\end{tabular}

\begin{tabular}{|c|c|c|}
\hline \multirow{4}{*}{ Paucibacillary } & & Sputum \\
\cline { 2 - 3 } & Negative & 1299 \\
\cline { 2 - 3 } & $1-3$ AFB/100 oil immersion field & 49 \\
\cline { 2 - 3 } & $4-9$ AFB/100 oil Immersion field & 140 \\
\hline \multirow{3}{*}{ Multibacillary } & $+(10-99$ AFB/100 oil Immersion field $)$ & 80 \\
\cline { 2 - 3 } & $++(1-10$ AFB/oil Immersion field $)$ & 126 \\
\cline { 2 - 3 } & $+++(>$ AFB/oil Immersion field $)$ & 255 \\
\cline { 2 - 3 } & Total & 1949 \\
\hline
\end{tabular}

Table 2: The grading for the Number of Observed bacilli was recorded according to the recommendations of the IUATLD 


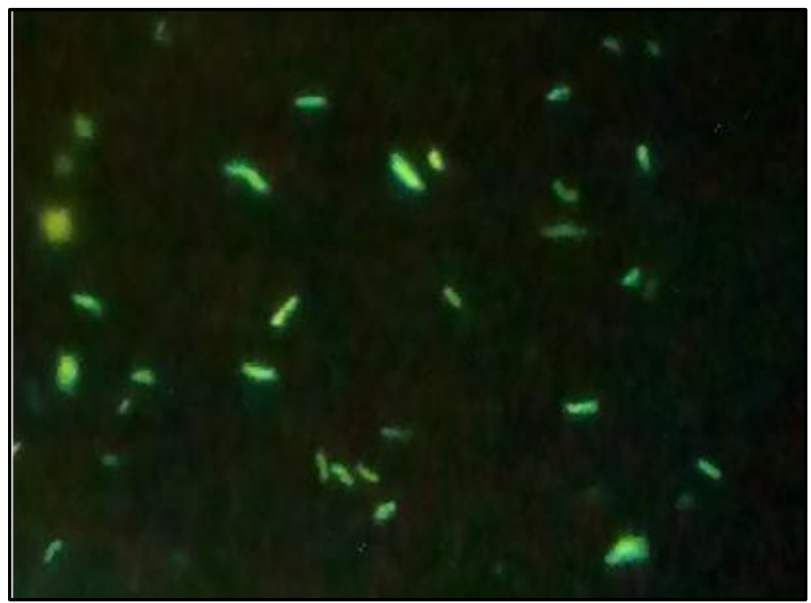

Fig. 1: Fluorescent AFB in AR Stain

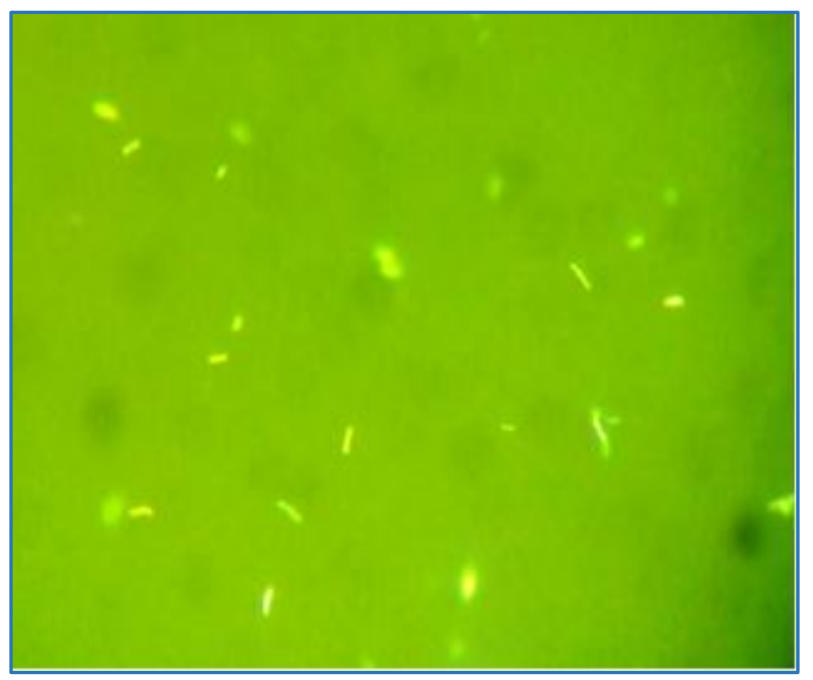

Fig. 2: AF AFB in PAP Stain

\section{DISCUSSION}

Tuberculosis is one of the commonest chronic disease affecting people throughout the world. Incidence of tuberculosis is low in developed countries, but in developing country like India it is still increasing reason may be due to rise in incidence of HIV and multidrug resistant tuberculosis. Since TB is highly infectious in early stage and treatment is long and cost effective, early diagnosis and accurate (Correct) treatment is mandatory.

In India prevalence of tuberculosis is 400 per 100,000 population. ${ }^{7}$ In present study prevalence of tuberculosis was (33.35\%). Males were more effected by tuberculosis in comparison to female reason behind that may be because they move to outside for their earning, so more exposure to the bacilli. The clinical presentation of tuberculosis is usually fever, cough, sputum, night sweat, haemoptysis, dyspnoea, weight loss, anorexia. But some time delay in diagnosis has often been attributed to atypical clinical presentation and radiological presentation. The diagnosis of tuberculosis is confirmed by the demonstration of Tubercular bacilli.

In present study we have diagnosed mycobacterium in (16.16\%) with ZN stain, whereas in same study we have diagnosed bacilli in (31.34\%) with fluorescent AR stain and $33.35 \%$ in AF stain [Table-1], which confirm Autofluorescent stain is slightly more sensitive in comparison to AR and more to $\mathrm{ZN}$ stain for the diagnosis of tuberculosis.
Our result were similar with Kupper et al. ${ }^{8}$ and Lunawat PP et al. ${ }^{9}$ in their studies, which also found AF stain was more sensitive in comparison with AR and ZN stain for the diagnosis of tubercular bacilli.

The PAP stain is routinely used in cytology, it saves the time and material that would be involved in any extra staining and also avoids the use of toxic or carcinogenic substances such as phenol and Rhodamine, which are used in AR staining method. It also offers the advantage of simultaneous identification of other agents such as pneumocystic carinii, aspergilla and candida in the material obtained primarily for the diagnosis of $\mathrm{TB}$, especially in immunocompromised patients. ${ }^{10}$

\section{CONCLUSION}

Tuberculosis is highly infectious disease, which is common among rural population in India. Males are more infected with it usually present with fever, cough, sputum and weight loss. Fluorescence microscopy is a useful, rapid, reliable and is quite economical tool for the diagnosis of mycobacterium bacteria in specimens for AFB in comparison to ZN staining. The PAP stain is routinely used in cytology, it saves the time and material that would be involved in any extra staining and also avoids the use of toxic or carcinogenic substances, such as phenol and Rhodamine, which are used in AR staining method.

\section{REFERENCES}

1. David HL. Bacteriology of the mycobacterioses. US Department of Health, Education and Welfare, PHS, CDC, Washington DC, 1976.

2. Wayne LG. Microbiology of tubercle bacilli. Am Rev Respir Dis 1982;125:31-41.

3. Huebner RE, Good RC, Tokars JI. Current practices in mycobacteriology: results of a survey of state public health laboratories. J Clin Microbiology 1993;31:771-5.

4. Ghali VS, Garcia RL, Skolom J. Fluorescence of Pneumocystic carinii in Papanicolaou smears. Hum Pathol 1984;15(10):907-909.

5. Kupper T, Gore C, Gore R, et al. Fluorescence microscopy of mycobacteria in pleural effusions. Cytopathology 1999;10:303-7.

6. Kupper TH, Wehle K, Pfitzer P. Fluorescence microscopy of Papanicolaou stained preparations. Acta Cytol 1994;38(4):64.

7. Mandal AK, Chaudhary S. Tuberculosis. In: Mandal AK, Chaudhary S, editor. Text book of pathology, Ist ed. New Delhi: Avichal Publisher; 2010:70-75.

8. Kupper T, Wehle K, Marzahn S, et al. The cytologic diagnosis of Mycobacterium kansasii tuberculosis by fluorescence microscopy of Papanicolaou stained specimens. Cytopathology 1995;6(5):331-8.

9. Priya P Lunawat (Munot), Amit A Mhapuskar, Ganvir SM, et al. Detection of acid fast bacilli in saliva using Papanicolaou stain induced fluorescence method versus fluorochrome staining: an evaluative study. Journal of International Oral Health 2015;7(7):115-120.

10. Hettlich C, Kupper TH, Wehle K, et al. Aspergillus in the Papanicolaou stain: morphology, fluorescence and diagnostic feasibility. Cytopathology 1998;9(6):381-8. 